\title{
In-plane shear behaviour by diagonal compression testing of brick masonry walls strengthened with basalt and steel textile reinforced mortars
}

\author{
Larisa Garcia-Ramonda ${ }^{\mathrm{a}, 1}$, Luca Pelà ${ }^{\mathrm{a}}$, Pere Roca ${ }^{\mathrm{a}}$, Guido Camata ${ }^{\mathrm{b}}$ \\ ${ }^{a}$ Department of Civil and Environmental Engineering, Universitat Politècnica de Catalunya \\ (UPC-BarcelonaTech), Jordi Girona 1-3, 08034 Barcelona, Spain. \\ ${ }^{b}$ Department of Engineering and Geology, University "G. D'Annunzio" of Chieti-Pescara, \\ viale Pindaro 42, I-65127 Pescara, Italy
}

\begin{abstract}
This paper presents an experimental study of the structural behaviour of masonry walls retrofitted with Textile Reinforced Mortar (TRM) to improve their in-plane shear strength and deformation capacity. The experimental programme consists in diagonal compression testing of ten specimens of clay brick and lime mortar masonry retrofitted with three different TRM systems: i) continuous bidirectional grids of basalt TRM, ii) discrete bands of unidirectional steel TRM and iii) continuous basalt TRM on the wall's inner face and bed joints structural repointing with near surface mounted helical stainless steel bars on the wall's outer face. Two of the specimens were tested two times, i.e. in the unreinforced condition and subsequently in the repaired configuration including basalt TRM retrofitting. The experimental results show that the adopted TRM solutions produce a beneficial increase of shear resistance and ductility, making them suitable for seismic retrofitting and post-earthquake repair.

Keywords: Diagonal Compression Test, Masonry, TRM, FRCM, SRG, NSM, Basalt Textile, Steel Textile, Shear Strength, Ductility,
\end{abstract}

\footnotetext{
${ }^{\star}$ Fully documented templates are available in the elsarticle package on CTAN

Email addresses: larisa.garcia.ramonda@upc.edu (Larisa Garcia-Ramonda), luca.pela@upc.edu (Luca Pelà), pere.roca.fabregat@upc.edu (Pere Roca), g.camata@unich.it (Guido Camata)

${ }^{1}$ Correponding Author
} 


\section{Introduction}

2 As one of the main historical construction materials, masonry is abundant in 3 the built cultural heritage of many earthquake-prone regions of the world. Re4 cent seismic events, such as L'Aquila 2009 (Italy), Canterbury 2010 (New Zea5 land), Emilia 2012 and Amatrice-Norcia-Visso 2016 (Italy) earthquakes, have shown the seismic vulnerability of existing masonry structures [1].

7 Different strengthening techniques, based either on traditional or innovat8 ive approaches, have been proposed during the last decades. Some of them 9 show severe limitations due to the incompatibility of the reinforcement with the masonry substrate [2, 3. Among the traditional techniques are repointing of mortar joints or transversal tying through the thickness 4, 5. However, the use of steel elements usually brings severe problems of reinforcement corrosion in the long term [6]. Another technique extensively used to strengthen multiple leaf masonry is the grouting injection technique, but is only adequate for poor masonry walls showing low compactness or inner voids. Innovative strengthening techniques based on Fibre Reinforced Polymers (FRP); mainly carbon, glass and aramid fibre, have been utilized profusely due to their high tensile strength, lightweight, relative ease of installation and resistance to corrosion. The research carried out on the use of FRP has shown its ability to enhance the in-plane strength of masonry walls [7, 8, 9, 10. However, FRP systems have shown meaningful limitations precluding their use in several cases. For instance, high or low temperatures might compromise the efficiency of FRP systems [11, and wet lay-up FRP applications are not possible either on moist surfaces or at low temperatures. In addition, FRP systems typically act as a vapour barrier and therefore cannot be used when permeability is required, as in the case of existing masonry structures [12. These drawbacks stem mainly from the epoxy matrix, which acts both as the binder of the fibres and the bonding agent between the composite and the substrate. The epoxy matrix is also the reason for FRPs irreversibility and possible early debonding from a weak substrate [13. An alternative solution to FRP systems consists in replacing the epoxy 
resins by inorganic matrices [14]. These composite systems are denominated Textile Reinforced Mortar (TRM), Fibre/Fabric Reinforced Cementitious Matrix/Mortar (FRCM), Inorganic Matrix-Grid (IMG), and Steel Reinforced Grout (SRG) if steel cords are embedded in the mortar matrix [15, 16, 17]. Different authors [18, 19] have indicated that the use of TRM can overcome most of FRPs limitations. It has been evidenced that TRM is also more compatible with the substrate [20, 21, 22, Recent research has been carried out on the application of TRM solutions to different masonry typologies, e.g. Glass TRM on rubble stone masonry [23, basalt and glass TRM on tuff stone masonry [24, 25, 26], steel cord textile on grey clay brick masonry [27], steel reinforced grout (SRG) on confined masonry walls [28, 29]. However, there is still limited literature on its application to brick masonry [30, 31].

The environmental awareness has recently shifted the attention towards new low environmental impact, eco-friendly and natural materials for construction and repair. As a result, reinforcing textiles from natural fibres are now under the spotlight, including basalt fibres due to their higher ductility than glass or carbon fibres 32. However, the literature shows only limited experimental results on the application of basalt TRM to masonry walls [33], being the available researches mainly focused on the study of the bond behaviour with stack bond prisms [34, 35, 36].

Within this context, this work presents an experimental programme evaluating the in-plane shear performance of three different TRM configurations. The first two solutions consist in a continuous bidirectional grid of basalt fibres and in a textile of unidirectional steel fibres, both of them embedded in a lime mortar matrix. For the steel TRM, two different yarn spacings are investigated to evaluate their influence on the shear response. The third solution consists in an asymmetric layout with basalt TRM on the inner face, and bed joints structural repointing with Near Surface Mounted (NSM) helical stainless steel bars on the outer face. This last configuration is suitable for historical façades with exposed bricks, as previously analysed in [21, 31, 37]. The reinforcement systems were applied on walls composed of solid handmade clay bricks and low 
strength lime mortar joints. This material is recurrent in many historical and existing masonry structures. The experimental programme consisted in the execution of diagonal compression tests (DCT) in order to assess the efficiency of the TRM systems for post-earthquake repair and seismic retrofit, in terms of stiffness, load bearing capacity and ductility.

The DCT is proposed by the Eurocode 8 and the Italian Guideline [38, 39] for the evaluation of the shear strength in unreinforced masonry (URM) walls under in-plane actions [40, 41. The different interpretative models of the DCT are based on the assessment of the principal stress at the centre of the panel inducing the diagonal cracking failure [42. According to [43, the shear failure in URM walls is caused by three distinct mechanisms: bed joint sliding, step joint sliding and diagonal shear cracking. One of the novelties of the present work consists in the execution of the DCT on walls previously weakened with a small intentional defect localized in the center of the panel. Such defect is created with the purpose of inducing a more regular crack pattern and thus less scattered experimental results.

Two URM specimens were tested, and subsequently retrofitted and tested again to evaluate the capability of the TRM systems for post-earthquake repair 44. Eight additional walls were tested directly in the retrofitted condition to evaluate the potential of the seismic strengthening solution. The experimental results are compared in terms of crack patterns, failure modes, shear strength, stiffness and ductility. The evaluation of the ductility of the structural members required the selection of a proper model to quantify and interpret correctly this parameter of paramount importance in the field of seismic design.

\section{Experimental Programme}

The experimental campaign was carried out at the Laboratory of Technology of Structures and Construction Materials (LATEM) at the Technical University of Catalonia (UPC-BarcelonaTech). This section presents the properties of the materials, the preparation of the specimens and the testing procedure. 


\subsection{Mechanical Characterisation of Materials}

The experimental programme investigated one of the most frequent material combinations in historical masonry, i.e. solid clay bricks and lime mortar joints.

For this purpose, handmade solid clay bricks, fired with traditional procedures, and a lime based mortar were used.

The bricks presented rough and irregular surfaces, and slightly variable dimensions due to their traditional way of manufacturing. The average dimensions were $310 \times 145 \times 45 \mathrm{~mm}^{3}$. Twenty prismatic brick samples with dimension $100 \times 100 \times 40 \mathrm{~mm}^{3}$ were cut from the units to evaluate the compressive strength. The samples were tested in compression according to EN 772-1:2011 [45] by using a load cell of $3000 \mathrm{kN}$ under load control. The compressive strength was corrected by a shape factor of 0.70 in order to obtain the normalized compressive strength of the brick $f_{b, c}$ [45]. The flexural strength of the brick $f_{b, f}$ was determined by three-point bending test on 10 units following the EN 772-6:2001 [46] and the EN 1015-11:1999 [47.

The mortar used to bind the units was based on a commercial premixed hydraulic lime mortar 48] classified as M5 according to EN 998-2:2010 49]. Limestone filler was added to the premixed mortar to reduce its compressive strength in order to replicate a lower strength historical material [50]. Following the EN 1015-11:1999, prismatic samples with dimensions $160 \times 40 \times 40 \mathrm{~mm}^{3}$ were prepared during the construction of each wall, to evaluate the strength of the mortar. Flexural strength $f_{m, f}$ was evaluated on nine prismatic specimens for each wall, while the compressive strength $f_{m, c}$ was assessed on the eighteen halves produced by the splitting of the samples under flexure. The mortar samples were tested using a load cell of $10 \mathrm{kN}$ under load control.

To assess the compressive behaviour of masonry, seven stack bond prism of five bricks and four running bond walls were tested in compression following EN 1052-1 [51. An average compressive strength of 6,50 MPa (C.O.V 9\%) [52] was obtained.

After the test of each wall, the remaining masonry was disassembled with the aim of extracting mortar samples from the bed joints. Mortar samples with 
dimensions $50 \times 50 \times 15 \mathrm{~mm}^{3}$ were cut from the joints extracted and subjected to the Double Punch Test (DPT) according to DIN 18555-9:1999 [53] for the determination of the compressive strength $f_{m, D P T}$. The samples were tested between $20 \mathrm{~mm}$ diameter loading plates by using a $10 \mathrm{kN}$ capacity load cell. The irregular surface of the mortar was regularized using gypsum powder in order to assure a homogeneous loading of the sample [54, 55].

The mortar matrix [56] used for the application of the textile fabric was a premixed NHL 3.5 natural hydraulic lime of M15 class according to EN 9982:2010 49]. Mortar matrix samples were tested after the application of the reinforcement in each strengthened wall in order to control its resistance. The mechanical characterization of the flexural strength $f_{r m, f}$ and the compressive strength $f_{r m, c}$ of the retrofitting mortar was carried out by using the same procedures and standards for the mortar used in the joints, except for the use of a load cell of $200 \mathrm{kN}$ for the compression tests.

Table 1 summarizes the experimental results from each test of component materials in terms of average values and coefficient of variations.

The materials for strengthening and repair of the masonry substrate included three different textiles embedded in mortar matrix, and a helical stainless steel rebars for joint repointing (JR). The first type of textile consisted in a bidirectional grid of low density basalt (LDB) fibres with steel micro-cords and $17 \times 17$ $\mathrm{mm}^{2}$ grid spacing. The second and third type of textiles consisted in unidirectional sheets of galvanized steel micro-cords. Each fibre comprises five cords, two of which are twisted around three straight cords to ensure an effective interlocking. The difference between the two textiles lies in the steel density, defined as the number of steel yarns per unit width, which is either $1.57 \mathrm{yarn} / \mathrm{cm}$ in the case of low density steel (LDS) or 3.14 yarn/cm for the medium density steel (MDS). Table 2 reports classification and relevant properties of the different products for reinforcement as provided by the manufacturer. 
Table 1: Mechanical properties of the bricks and mortar used for the construction of the walls and the mortar matrix used for their reinforcement

\begin{tabular}{cccc} 
Brick & $f_{b, c}[\mathrm{MPa}]$ & $f_{b, f}[\mathrm{MPa}]$ & \\
\hline Average & 17.99 & 2.44 & \\
Number of Samples & 20 & 10 & \\
C.O.V & $8.30 \%$ & $20.00 \%$ & \\
& & & \\
Mortar & $f_{m, c}[\mathrm{MPa}]$ & $f_{m, f}[\mathrm{MPa}]$ & $f_{m, D P T}[\mathrm{MPa}]$ \\
\hline Average & 2.51 & 0.66 & 4.76 \\
Number of Samples & 176 & 88 & 496 \\
C.O.V & $24.25 \%$ & $24.00 \%$ & $18.53 \%$ \\
& & & \\
Matrix Mortar & $f_{r m, c}[\mathrm{MPa}]$ & $f_{r m, f}[\mathrm{MPa}]$ & \\
\hline Average & 14.04 & 4.34 & \\
Number of Samples & 120 & 60 & \\
C.O.V & $10.50 \%$ & $17.70 \%$ & \\
\hline
\end{tabular}

Table 2: Mechanical properties of the products used for the reinforcement of the walls as provided by the manufacturer

\begin{tabular}{|c|c|c|c|c|c|c|c|}
\hline Product & $\begin{array}{l}\text { Young's } \\
\text { modulus } \\
\text { E [GPa] }\end{array}$ & $\begin{array}{c}\text { Ultimate Tensile } \\
\text { Strength } \\
\sigma_{u, f}[\mathrm{MPa}]\end{array}$ & $\begin{array}{c}\text { Strain at failure } \\
\varepsilon_{u, f}\end{array}$ & $\begin{array}{l}\text { Thickness } \\
t f[\mathrm{~mm}]\end{array}$ & $\begin{array}{l}\text { Area single } \\
\quad \text { yarn } \\
A_{\text {filo }}\left[\mathrm{mm}^{2}\right]\end{array}$ & $\begin{array}{l}\text { Area Cord } \\
A_{\text {cord }}\left[\mathrm{mm}^{2}\right]\end{array}$ & $\begin{array}{c}\text { Tensile capacity } \\
\text { from shear bond test } \\
\sigma_{s l, t}[\mathrm{MPa}]\end{array}$ \\
\hline LDB & 90 & 1700 & 0.019 & 0.032 & - & - & 945.50 \\
\hline LDS & 190 & 2800 & 0.015 & 0.084 & 0.1076 & 0.538 & 1452 \\
\hline MDS & 190 & 3000 & 0.02 & 0.169 & 0.1076 & 0.538 & 839 \\
\hline $\mathrm{JR}$ & 160 & 1250 & 0.055 & - & - & - & - \\
\hline
\end{tabular}

\subsection{Specimen features}

Ten double leaf masonry walls with nominal dimensions $1270 \times 1270 \times 310$ $\mathrm{mm}^{3}$ were built in the laboratory. The specimens were built on a metallic Cprofile in Flemish bond with 21 courses and $15 \mathrm{~mm}$ mortar joints. The bricks were wet by immersing them in a bucket of water for one minute in order to avoid the absorption of the water of the mortar during the construction of the walls. A sliding interface between the base of the masonry wall and the surface of the metallic profile was generated by inserting a $3 \mathrm{~mm}$ thick Teflon sheet and a $3 \mathrm{~mm}$ thick PVC sheet (see Figure 2). This interface was necessary in order to 
allow the horizontal sliding of the base of the wall during the test. The finished walls were stored under laboratory conditions during the curing of the mortar.

Two walls were built with a defect in the central brick of the 11th course, intentionally created to induce a regular diagonal crack pattern. The brick in the centre of the panel was cut in the middle in order to create a $4 \mathrm{~mm}$ thick notch, not filled with binding mortar. These two URM specimens were tested twenty-eight days after their construction. After the tests, they were repaired and retrofitted with LDB, and then tested again twenty-eight days after the repair. The remaining eight specimens were strengthened twenty-eight days after the construction, and then tested twenty-eight days later.

Figure 1 shows the procedure followed for strengthening the wall specimens with the TRM systems. The surfaces of the walls were prepared by removing the dust with a vacuum and by creating grooves along the mortar joints in order to generate the necessary grip between the wall's surface and the mortar matrix of the TRM, see Figure 1 a. The specimens were wet with abundant water to prevent masonry from absorbing the water during the application of the composite. The first layer of mortar matrix was applied on the surface of the specimen, shown in Figure 1 b,e. Then the textile was embedded in the matrix by applying a light pressure on the textile to guarantee the right adherence to the support and to fill all the voids of the mesh, see Figure 1 c,e. The sheets of LDB grids had a width of $800 \mathrm{~mm}$. Two sheets were applied on each side of the wall with an overlap of $300 \mathrm{~mm}$ in the centre of the panel. The overlapping length was based on the bond length results obtained in [35, 57] and was designed to assure a satisfactory stress transfer between the substrate and the TRM. The strips of LDS and MDS had a width of $100 \mathrm{~mm}$. A second layer of mortar matrix was applied to cover completely the fibres, as shown in Figure 1]d,f. The final thickness of the TRM reinforcement varied between 8 to $10 \mathrm{~mm}$. The procedure was repeated at both faces of the specimen. Once the hardening of the mortar had begun, the faces were wet to favour the curing and then were wrapped with sackcloth fabric, which was kept wet for the following 7 days, see Figure 1 h. Once the fabric was wet, it was wrapped with plastic 


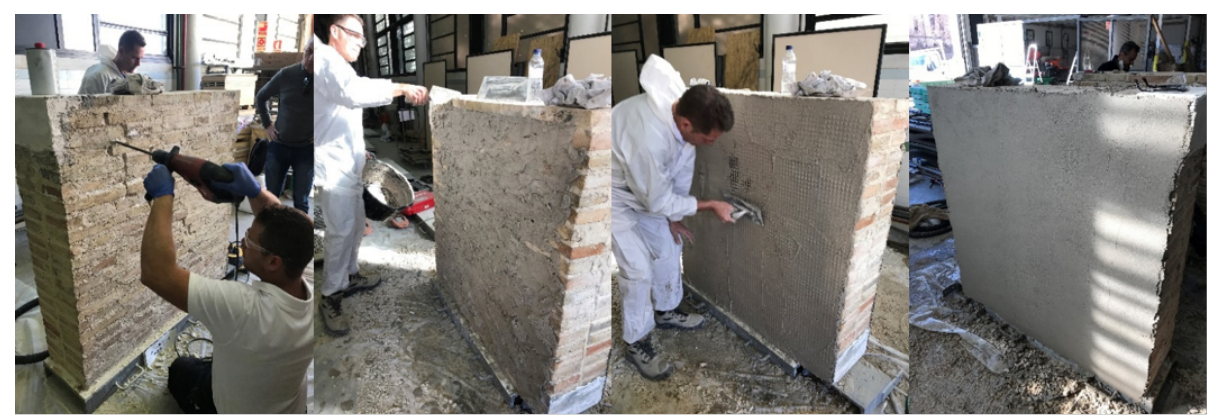

a)

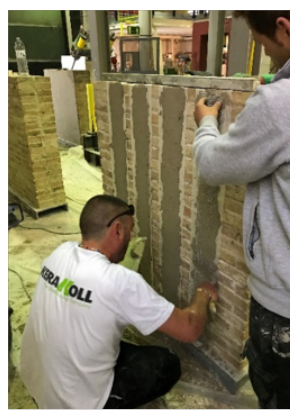

e) b) d)

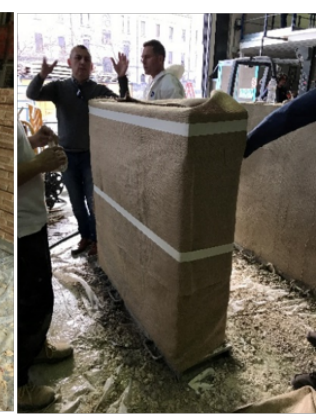

h)

Figure 1: Procedure for the application of the TRM systems: a) creation of grooves along the mortar joints, b) application of the first layer of mortar, c) set of the fibre net, d) finished look of the wall retrofitted with basalt TRM, e) application of the first layer of vertical mortar strips, f) finished look of the wall retrofitted with steel TRM, g) insertion of the helical stainless steel rebar, h) wrapping of the specimens with wet sackcloth fabric for curing

The specimens were labelled with an alphanumeric identifier using the notation $\mathrm{X}_{-} \#$, where " $\mathrm{X}$ " is the tag denoting unreinforced masonry (URM) or one of the reinforcement systems LDB, LDS, MDS, LDB-JR. The final digit "\#" is a number ( 1 or 2$)$ used to identify each specimen since they were tested in pairs 
to checks the repeatability of the results. The URM specimens that were later repaired and retrofitted with $\mathrm{LDB}$ are denoted by the "R" tag.

\subsection{Experimental Setup}

The standard ASTM E519M [58] was used as reference for the execution of the DCT. However, a different setup that those suggested by the aforementioned standard was designed to allow the application of the diagonal compression load without requiring the 45 degree rotation of the walls. This modification was necessary because the specimens could experience damage during the rotation operation due to their low strength binding mortar.

The specimens were set on a metallic bench consisting of two parallel $\mathrm{H}-$ Shape beams anchored to the strong floor of the laboratory. Each metallic profile, supporting the specimens, was bolted on top of the bench in order to avoid its displacement during the execution of the test. Two steel wedges were placed at two diagonally opposite corners of the specimen. Each wedge was welded to a robust beam consisting of $2 \mathrm{C}$ Channels placed back to back and stiffened with ribs. The beams at opposite corners were connected with two dywidag bars. The gap between the steel wedges and the corners of the masonry specimens was filled with a layer of epoxy resin and a sheet of compressed wood to smooth the loading surface. The load was applied by using two hydraulic actuators which provided the diagonal force by pulling the dywidag bars, as shown in Figure 2. 


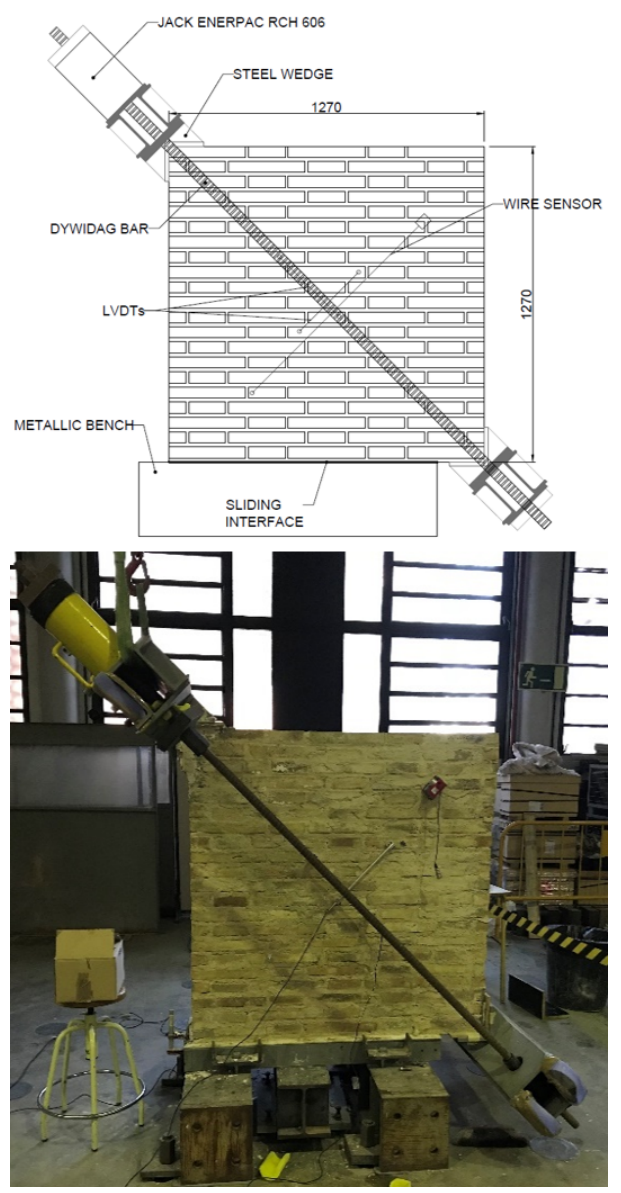

Figure 2: Setup of the Diagonal Compression Test

The hydraulic actuators, with load capacity of $600 \mathrm{kN}$, were controlled through the oil pressure of the central pump, which was measured with a pressure transducer. The tests were all performed under displacement control. At the beginning of each test, three cycles were executed, in the range from $10 \mathrm{kN}$ to $50 \mathrm{kN}$, and then the load was monotonically increased until failure. The displacement was applied at a constant rate of approximately $0.5 \mathrm{~mm} / \mathrm{min}$. The tests were stopped when the reduction in strength with respect to the peak load was about $50 \%$, in order to capture correctly the post-peak softening behaviour. The specimens were instrumented with four linear variable differential 
transducers (LVDT), having a displacement range of $\pm 5 \mathrm{~mm}$ and a precision of $5 \mu \mathrm{m}$, and two wire sensors of $1000 \mathrm{~mm}$ and a precision of $0.01 \mathrm{~mm}$, as shown in Figure 2. The LVDTs were mounted along the diagonals on both sides of the specimen, in order to measure the shortening of the closing diagonal (under compression) and the elongation of the opening diagonal (under tension). The wire sensors were also mounted along the opening diagonal with a gage length of $900 \mathrm{~mm}$.

\section{Experimental results}

This section presents the methodology considered for the computation of shear strength, stiffness and ductility capacity. The behaviour of the specimens is presented in terms of cracking patterns and experimental curves $F-\delta$ (Load - displacement). The displacement is calculated from the average readings of the LVDTs located on both sides of the wall. Table 3 summarizes the main parameters obtained.

\subsection{Shear strength and shear stiffness}

Two standards, ASTM-E519 [58] and RILEM TC 76-LUM [59], provide criteria on how to evaluate the main results of the DCT. The ASTM and the RILEM standards use Equation (1) and Equation (2) respectively to evaluate the shear stress at the centre of the wall, being $P$ the applied load and $A_{n}$ the net area of the panel:

$$
\begin{gathered}
\tau_{A S T M}=0.707 \times \frac{P}{A_{n}} \\
\tau_{R I L E M}=1.05 \times \frac{P}{A_{n}}
\end{gathered}
$$

Both standards assume an isotropic linearly elastic model. However, the ASTM standard [58] assumes a pure shear stress state in the centre of the panel. Consequently, the Mohr's Circle is centred in the $\tau-\sigma$ plane and the value of the shear strength is computed as Equation 1. In turn, the interpretation of 
the RILEM standard [59] is based on the theory of Frocht 60]. According to Frocht's formulation, a non-uniform shear stress takes place along the loaded diagonal of the specimen subjected to diagonal compression. Therefore the Mohr's circle, corresponding to the centre of the panel, is not centred in the $\tau-\sigma$ plane and the shear stress is computed according to Equation 2.

In addition, the shear strain $\gamma$ and the shear modulus of elasticity $G$ can be calculated as follows:

$$
\begin{gathered}
G_{A S T M}=\frac{\tau_{A S T M}}{\gamma} \\
G_{R I L E M}=\frac{\tau_{R I L E M}}{\gamma} \\
\gamma=\varepsilon_{c}+\varepsilon_{t}
\end{gathered}
$$

where $\varepsilon_{c}$ and $\varepsilon_{t}$ in Equation (5) are the strains along the shortening (compressed) diagonal and the elongating (tensioned) diagonal of the panel, obtained from the average readings of the LVDTs located on both sides of the wall. In turn, the initial shear stiffness modulus $G$ is calculated as the secant modulus between the origin and the shear stress at the first shift of the slope in the $\tau-\gamma$ curve, which corresponds, on average, to the $30 \%$ of the maximum stress. Two different values of $G$ can be calculated by considering the estimations of shear stresses by either ASTM or RILEM standards, see Equations (3) and (4).

The ductility is the ability that the structure has to sustain large deformations in the inelastic domain of the response. The ductility factor is calculated as $\mu=\gamma_{u} / \gamma_{y}$, is considered to characterize the post-peak performance of the shear response. The ultimate shear strain $\gamma_{u}$ is calculated as the post-peak strain for which the corresponding stress reaches a reduction of $20 \%$ with respect to the peak one, following Prota et al. [24, Parisi et al. 61, Marcari et al. 62. and Balsamo et al. 25]. The available approaches in the literature evaluate the yield strain $\gamma_{y}$ according to different criteria. Marcari et al. 62 idealizes the experimental stress-strain curve with a bilinear law and calculates the yield 
strain $\gamma_{y}$ by using the shear secant modulus of the $\tau-\gamma$ initial branch at $70 \%$ of $\tau_{\max }$. The values of $\tau_{y}$ and $\gamma_{y}$ are determined with an energy equivalence by equating the areas below the experimental curve and the bilinear idealization. Gattesco et al. 63] define $\gamma_{y}$ as the elastic shear deformation corresponding to a value of the load equal to the peak load. The shear strain $\gamma_{y}$ is given by the ratio between the peak strength and the shear modulus G, as shown in Figure 3.

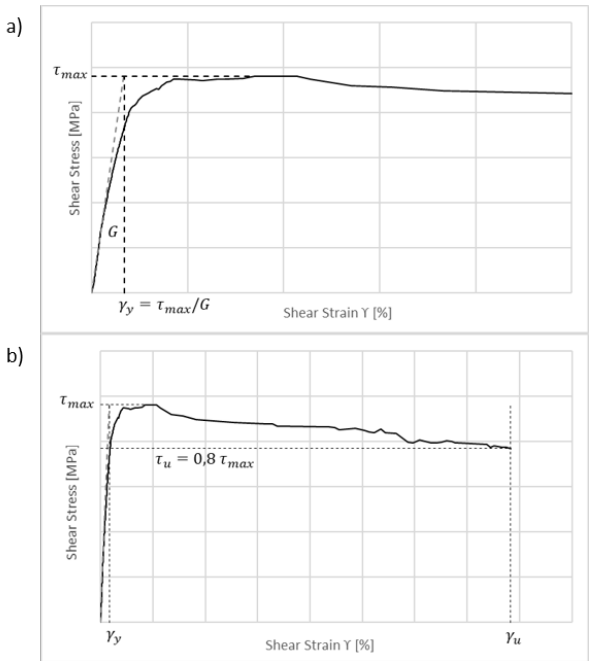

Figure 3: Evaluation of the ductility according to the approach proposed by Gattesco et al. 63. a) evaluation of $\gamma_{y}$ given by the ratio between the peak strength and the shear modulus $G$, b) evaluation of $\gamma_{u}$ which represents the ultimate shear strain corresponding to $20 \%$ shear strength reduction

The experimental tests carried out in the present research exhibited pronounced hardening behaviours after the initial linear loading branch and before reaching the peak resistance. Due to this phenomenon, it was of paramount importance to select an appropriate approach to evaluate the ductility factor. Since the methods presented in [24, 25, 61, 62 would underestimate drastically the ductility factor due to the existence of such hardening, this research considers the approach proposed by Gattesco et al. 63. to obtain more consistent and realistic evaluations of the yielding strain. 


\subsection{Behaviour of tested specimens}

\subsubsection{Unreinforced samples and specimens retrofitted with basalt TRM}

The unreinforced specimens, URM_1 and URM_2, exhibited qualitatively a similar behaviour in the elastic range. The URM specimens showed a sudden drop in resistance shortly after the appearance of the diagonal crack. The crack started from the induced defect and propagated towards the opposite corners of the specimen. The failure of both specimens was characterized by a stairstepped diagonal crack pattern through the bed joints and opening head joints, as well as tensile splitting in the bricks, especially in URM_1, as shown in Figure 4.

a)

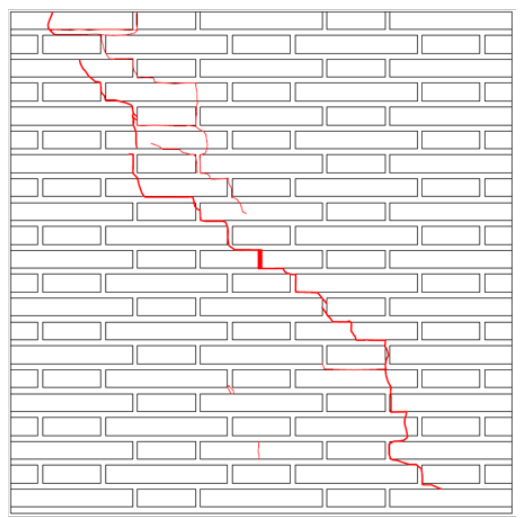

b)

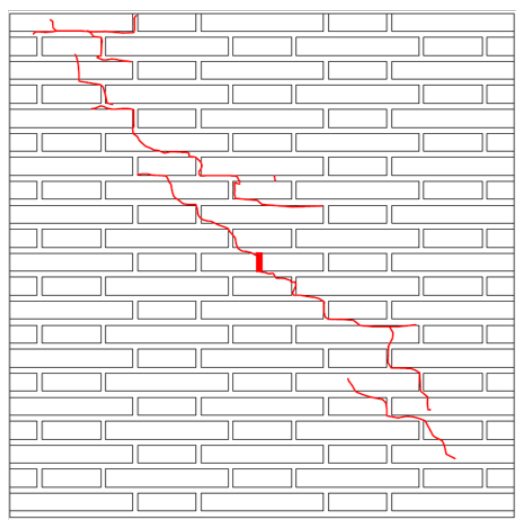

Figure 4: Crack patterns of URM specimens. a) URM_1, b) URM_2

The peak load was $179 \mathrm{kN}$ in URM_1 ( $\delta=0.15 \mathrm{~mm}, \gamma=0.047 \%$ ), while in 
URM $\_2$ the peak load was $115 \mathrm{kN}(\delta=0.25 \mathrm{~mm}, \gamma=0.075 \%)$. Specimen URM_2 exhibited a rather stable load carrying capacity in the softening branch, while URM_1 showed a more pronounced softening behaviour. Although the intentional defect in the centre of the wall induced controlled crack patterns and failure mechanisms, the shear capacity resulted scattered in the two specimens probably due to the variation of the mechanical properties of the masonry components. Another possible reason is the prevalent tensile splitting of units along the diagonal crack of wall URM_1 that causes higher shear capacity, as also found by other authors [24, 30, 64].

These damaged walls were subsequently repaired by filling the cracks with the same lime based mortar used for retrofitting. After being repaired they were retrofitted with LDB and tested again. The purpose was, as already mentioned in Section 1, to assess the behaviour and effectiveness of the TRM as a postearthquake repair system. Both specimens, URM1_R and URM2_R, exhibited qualitatively similar behaviour. An initial linear elastic behaviour was observed until the reopening of the repaired cracks in the masonry. The first crack appeared around $60-80 \%$ of the maximum load, causing a momentary drop of the load resisted and a reduction of the stiffness. This phenomenon may be associated to load transmission from the masonry to the reinforcement system. After this point, a progressive recovery of the load and the stiffness was observed, while a major number of small and diffused cracks appeared along the diagonal and parallel to the first one. These cracks propagated gradually towards the edges of the specimens as the load increased. The cracks widened due to the progressive deformation until the end of the test.

The peak load was $272 \mathrm{kN}$ for URM1_R $(\delta=3.38 \mathrm{~mm}, \gamma=0.98 \%)$ while for URM2_R was $241 \mathrm{kN}(\delta=4.12 \mathrm{~mm}, \gamma=1.20 \%)$. The post-peak branch was characterized by a significant residual resistance, which was due to a soft decrease of the shear resistance as a consequence of the progressive redistribution of stresses along the bidirectional grid. The gradual deformation of the specimen led to the failure of some of the yarns of the grid, see Figure 5 . The redistribution of stress throughout the basalt grid can be recognized in the fact that the diagonal 
a)

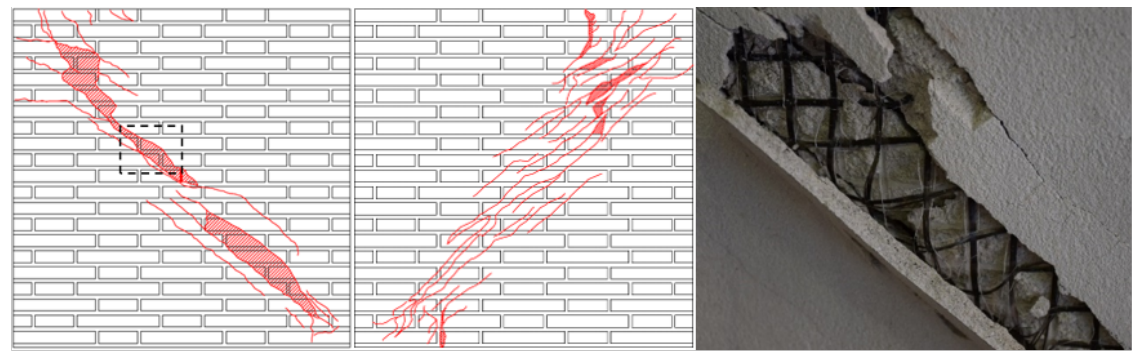

b)

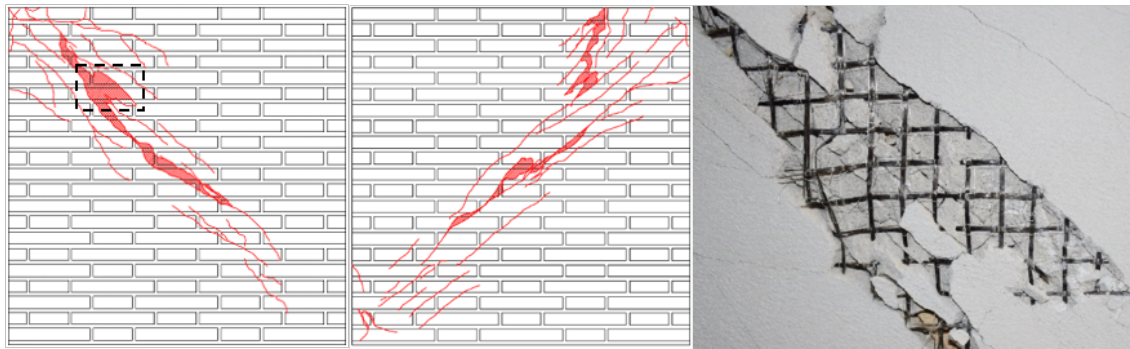

Figure 5: Crack patterns of damaged URM specimens repaired and retrofitted with basalt TRM and zoom on the failure of some yarns at the end of the test. a) URM1_R, b) URM2_R

crack pattern is distributed over a wider area.

The repaired specimens exhibited an elastic stiffness very similar to that of the URM specimens, i.e. a full recovery of the undamaged stiffness after the repair intervention. The basalt grid reinforcement homogenized the response of the repaired specimens producing a more similar ultimate capacity compared to the URM ones. In terms of deformability, the ultimate shear strain $\gamma_{u}$, associated with the drop of $20 \%$ of the maximum shear stress, was $1.71 \%$ for the specimen URM1_R and 1.95\% for the specimen URM2_R. These values were of $0.26 \%$ for URM_1 and $1.06 \%$ for URM_2.

The LDB was also applied as reinforcement to undamaged masonry specimens. Three different phenomena were recognized after analysing the response of these strengthened panels. First, the cracking of masonry, second the cracking of the mortar matrix and third the failure of the yarns of the basalt textile. This sequence is in agreement with the response revealed by previous studies on composites subjected to tensile test [34, 65].

Specimens LDB_1 and LDB_2 showed similar linear trends up to $70 \%$ of the 
peak load. Up to this point, no damage was observed on the mortar coating, even though a decrease of the slope of the experimental curve $F-\delta$ was recorded by the instruments. The first crack became visible, above the compressed diagonal, at almost $90 \%$ of the peak load. After the appearance of these first hairline cracks, a large number of thin parallel cracks developed in the centre and started propagating towards the loaded edges along the compressed diagonal. As soon as the peak load was reached, several parallel cracks developed and crossed almost completely the diagonal of the specimens over a diffused width. At this stage, the specimen LDB_1 presented a peak load of $310 \mathrm{kN}(\delta=0.44 \mathrm{~mm}$, $\gamma=0.13 \%)$ while the specimen LDB_2 reached $279 \mathrm{kN}(\delta=0.58 \mathrm{~mm}, \gamma=0.21 \%)$ After the peak load, a progressive reduction of the resistance of the specimens was observed. The softening branch of both specimens was due to a gradual widening of the cracks, spalling of the matrix cover and consequent exposition of the bare textile. The progressive failure of some of the yarns generated a drop of the resistance in the post-peak branch, followed again by a gradual decrease of the resistance. However, the overlapping of the net of $300 \mathrm{~mm}$ in the centre of the walls did not undergo any detachment from the surface, showing the good compatibility between the LDB and the masonry substrate. This outcome confirms the evidence from previous studies [57, 66], in which the effective bond length was greater than $200 \mathrm{~mm}$. Figure 6 shows the crack patterns of the specimens at the end of the test. Figure 7 presents the experimental curves $F-\delta$ (Load - displacement) of unreinforced specimens (URM), repaired specimens and retrofitted specimens with basalt TRM.

The repaired and retrofitted specimens exhibited an average increase of $177 \%$ of the ultimate shear deformation. Similarly, the basalt reinforcement showed significant impact in the post-peak behaviour of the retrofitted specimens by providing tensile strength after the masonry cracked, and yielding a remarkable ductility compared with the unreinforced configuration. Thus the ultimate shear strain $\gamma_{u}$ of specimen LDB_1 was $0.73 \%$, whereas that of specimen LDB_2 was $1.57 \%$. This scatter was caused by the earlier rupture of some of the yarns of the textile in the first specimen. Nevertheless, the average increase was of $74 \%$. 
For both the cases of repaired and retrofitted specimens, the presence of the basalt grid homogenized the behaviour, reduced the scatter of the results and increased the peak load and ductility.

a)

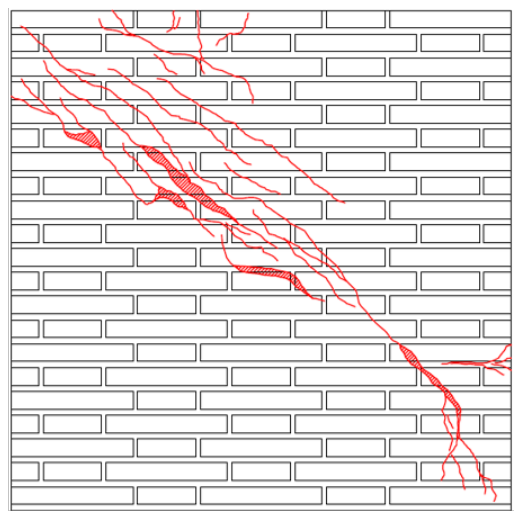

b)

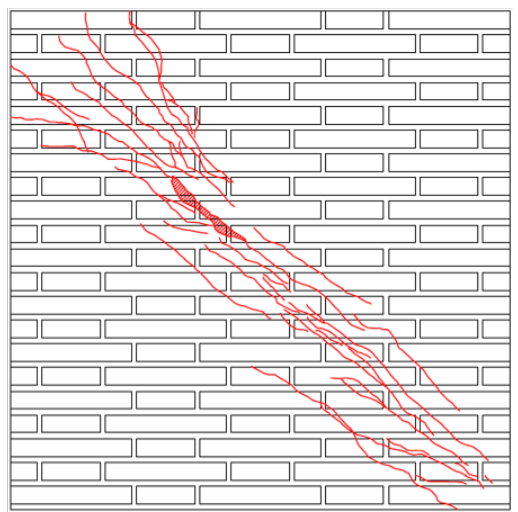

Figure 6: Crack patterns of specimens retrofitted with basalt TRM. a) LDB_1, b) LDB_2 


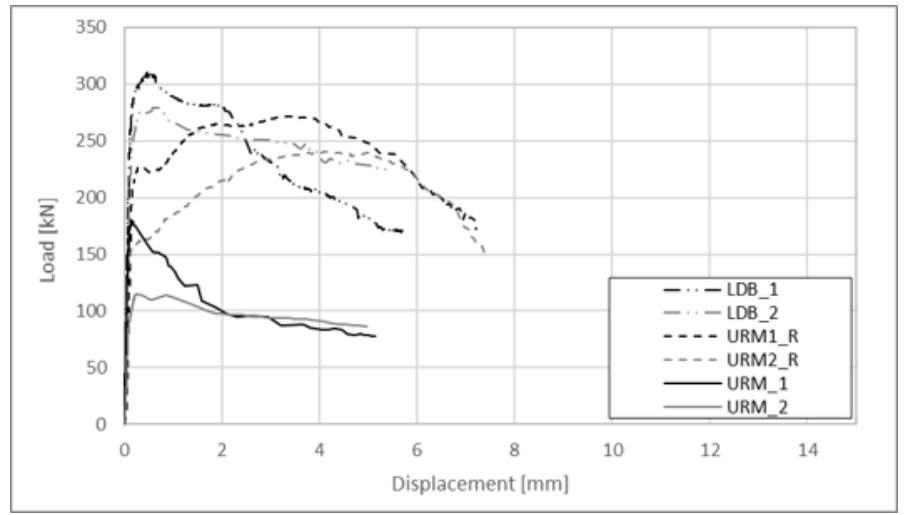

Figure 7: Comparison of the diagonal compression load vs. opening displacement curves of unreinforced specimens (URM), repaired specimens and retrofitted specimens with basalt TRM (LDB)

\subsubsection{Specimens retrofitted with steel TRM}

The LDS and MDS unidirectional textiles were installed with a layout composed of four horizontal and four vertical $100 \mathrm{~mm}$ wide strips.

Figure 8 shows the $F-\delta$ experimental curves of the four specimens, LDS_1, LDS_2, MDS_1 and MDS_2. Each pair of specimens presented, qualitatively, similar responses with a linear trend up to $50-60 \%$ of the peak load. After this point, a decrease of the slope of the $F-\delta$ experimental curves was detected, indicating that masonry was cracking even though no visible cracks could be observed from the exterior. In the cases of LDS specimens, the first cracks appeared, above the compressed diagonal, at $80-90 \%$ of the maximum load. For the MDS specimens, the first diagonal cracks were detected after the peak load mainly in the centre of the panel along the compressed diagonal. The cracks in all the cases were diffused, and mainly located in the mortar coating of the strips, as shown in Figure 9 .

Specimen LDS_1 reached a peak load of $320 \mathrm{kN}(\delta=0.27 \mathrm{~mm}, \gamma=0.077 \%)$ whereas LDS_2 reached $237 \mathrm{kN}(\delta=1.36 \mathrm{~mm}, \gamma=0.41 \%)$ Specimen MDS_1 reached a peak load of $233 \mathrm{kN}(\delta=1.71 \mathrm{~mm}, \gamma=0.54 \%)$ and specimen MDS_2 attained a peak load of $222 \mathrm{kN}(\delta=1.16 \mathrm{~mm}, \gamma=0.34 \%)$ 
The two types of specimens showed some specific features in their post-peak branch. LDS_1 presented a noticeable constant decrease of the resistance until a diagonal displacement of $3.45 \mathrm{~mm}$ (shear deformation of $1.0 \%$ ), where the load became almost stable. LDS_2 showed an increasing deformation under almost constant load until $3.5 \mathrm{~mm}$ (shear deformation of 1.06\%). Despite this difference, the post-peak softening of LDS specimens presented several drops in the resistance, as a result of subsequent local debonding phenomena of some portions of the strips. The specimens retrofitted with MDS showed an almost horizontal branch immediately after the peak load, until a diagonal displacement of $3.0 \mathrm{~mm}$ (shear strain of $0.85 \%$ ) was reached. After this stage, the specimen MDS_1 experienced a drop of its resistance caused by the delamination of the horizontal strips, followed by a series of local debonding phenomena, which can be clearly identified on the experimental curve. The specimen MDS_2 evidenced a more gradual and progressive decrease of its resistance.

Finally, no failure of steel fibres was observed in any of the samples, as also evidenced in another previous experimental programme with steel TRM [27. However, the LDS samples experienced debonding from the masonry substrate at the end of the strips near the edges of the specimens, while MDS samples were characterized by the delamination of the textile within the matrix rather than the debonding from the substrate. The possible cause of this phenomenon may be the lower spacing between cords in MDS-TRM which provided lower interlocking to the mortar matrix. Figure 9 shows the crack patterns as well as the debonding and delamination detected on the four specimens at the end of the test.

\subsubsection{Asymmetrically reinforced specimens with basalt TRM and bed joints re- pointing}

The asymmetric system was composed of a bidirectional LDB grid on one face of the wall, and NSM stainless steel rebars on the other face. Helical rebars were inserted with vertical spacing equal to three courses in order to balance the contribution of the basalt mesh and thus to provide similar in-plane strength 


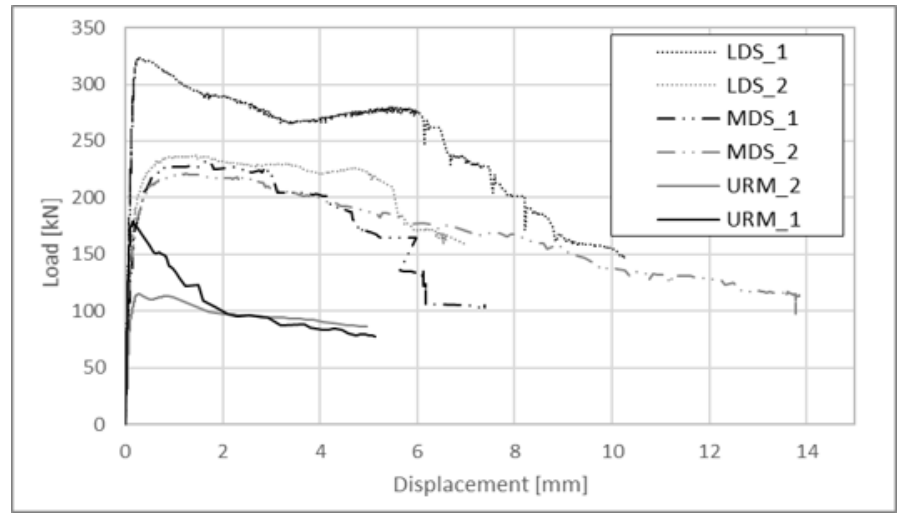

Figure 8: Comparison of the diagonal compression load vs. opening displacement curves of unreinforced specimens (URM) and specimens retrofitted with steel TRM consisting of unidirectional strips (LDS and MDS)

on both faces of the walls.

Even though the slope $(G)$ of the initial linear behaviour was different in the specimens, the global behaviour of the two specimens with asymmetrical strengthening showed similar features. Both showed linear trends up to $70 \%$ of the peak load. Up to this point, even if no damage was observed on the exterior mortar coating, the instruments detected a slight change in the stiffness (see Figure 10). The first cracks, on the side of the basalt grid, were visible at almost $95 \%$ of the peak load. These cracks were diffused throughout the width and along the compressed diagonal. At the same time, the other side with the joint repointing experienced the formation of a series of stair-stepped cracks through the bed and head joints, spreading from the centre towards the corners. Specimen LDB-JR_2 exhibited more splitting failures of bricks than specimen LDB-JR_1, which might explain its higher peak load. After these first thin cracks appeared on the mortar coating of the basalt grid, a major number of thin parallel cracks developed and started propagating towards the loaded edges along the compressed diagonal. After the peak load, widening of the cracks under progressive compressive displacement was observed at both sides.

The post-peak branches of the specimens were characterized by a gradual 
a)

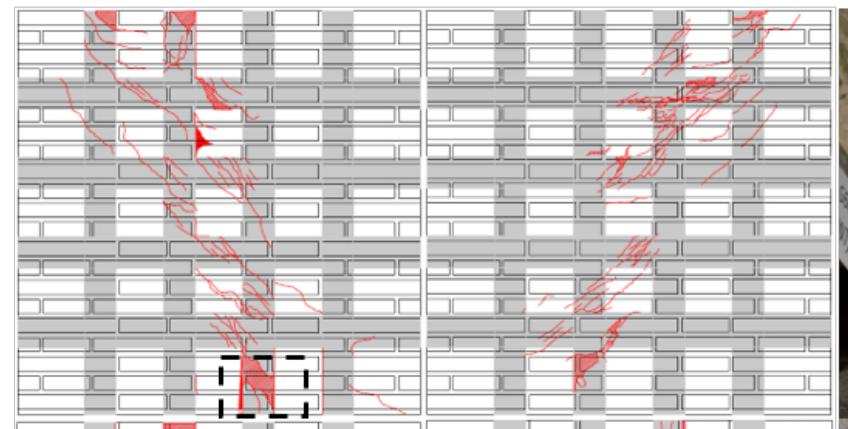

b)

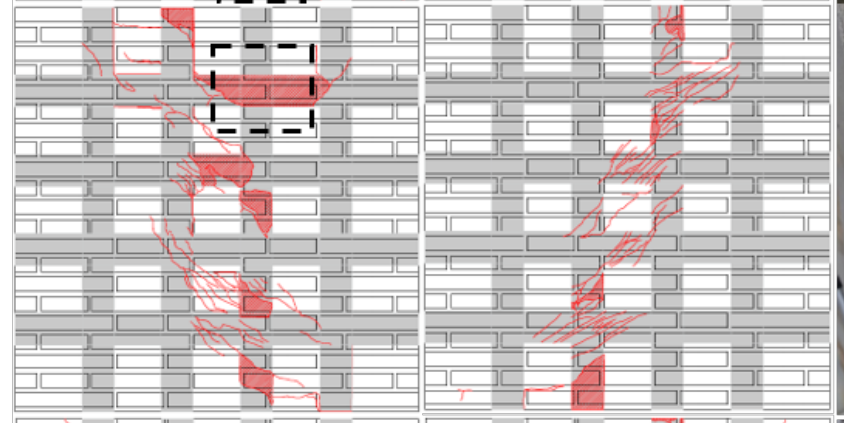

c)

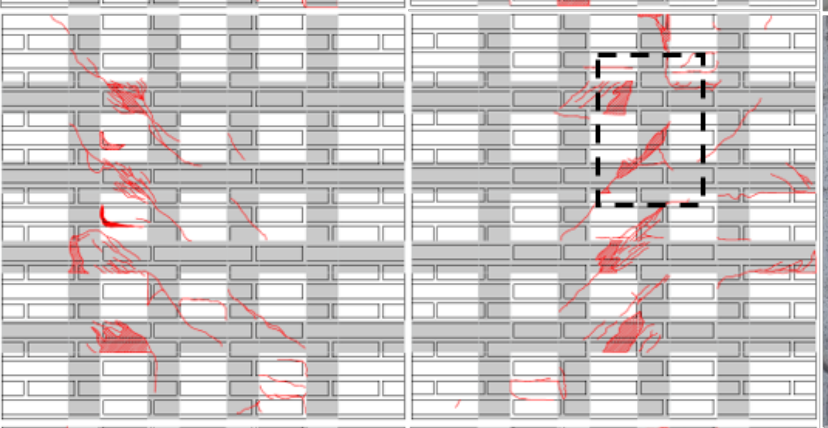

d)
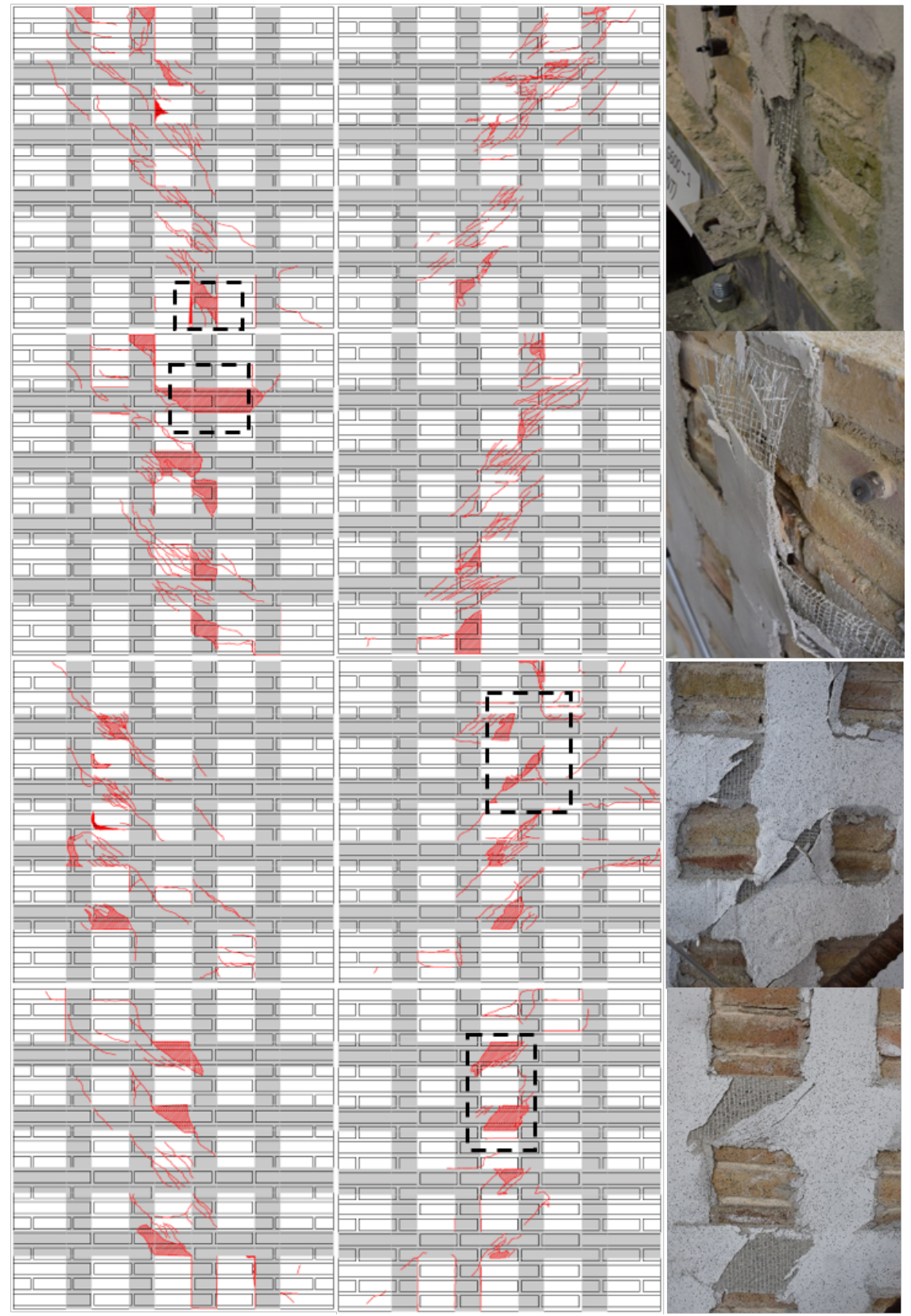

Figure 9: Crack patterns of specimens retrofitted with steel TRM and zoom of the debonding of LDS strips and delamination within the matrix of MDS, a) LDS_1, b) LDS_2 c) MDS_1, d) MDS_2 
decrease of the resistance. This progressive reduction was caused by the complex cooperation between the strengthening effect of the basalt grid at one side and that of the NSM helical rebars at the other. The rupture of some of the yarns of the basalt grid occurred at almost the end of the test followed by a reduction of the marginal resistance, as observed in the experimental curves. No rupture of the helical rebars was registered. Figure 11 shows the final crack pattern observed in the specimens.

The specimen LDB-JR_1 reached a peak load of $185 \mathrm{kN}(\delta=0.45 \mathrm{~mm}, \gamma=0.14 \%)$ whereas the specimen LDB-JR_2 reached a peak load value of $199 \mathrm{kN}(\delta=0.73$ $\mathrm{mm}, \gamma=0.23 \%$ ) The basalt grid and the helical rebars had a great impact on the post-peak behaviour, providing tensile strength after the cracking of masonry and allowing the specimen to develop a more ductile behaviour. The ultimate shear strain $\gamma_{u}$ of specimen LDB-JR_1 was 1.67\%, whereas for specimen LDBJR_2 it was $1.42 \%$.

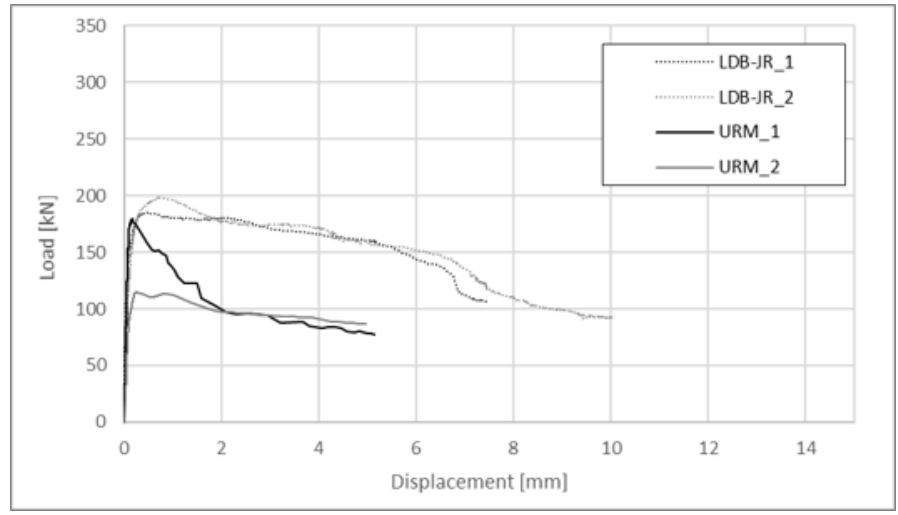

Figure 10: Diagonal compression load vs. opening displacement curves of unreinforced specimens (URM) and specimens retrofitted with Basalt TRM in one side and joint repointing in the other (LDB-JR) 
a)

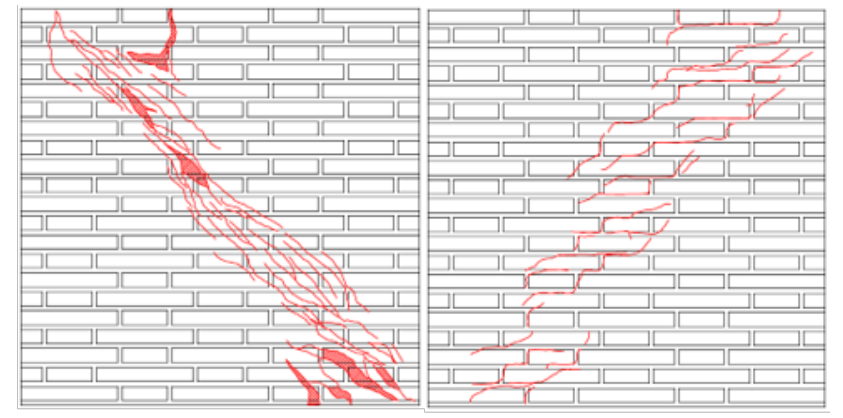

b)

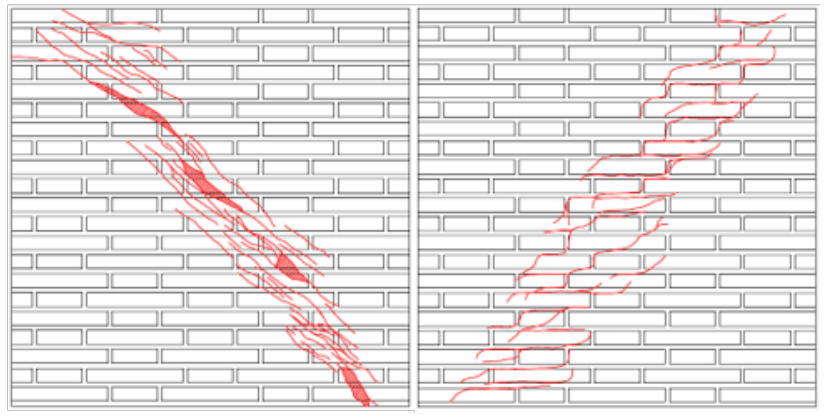

Figure 11: Crack patterns of specimens retrofitted with Basalt TRM in one side (left) and joint repointing in the other side (right): a) LDB-JR_1, b) LDB-JR_2

\section{Discussion}

This section presents a comparative analysis of the experimental results described in the previous sections. The responses of the different TRM strengthening solutions are compared with the average value of the URM walls in order to evaluate the gain in structural performance. Table 3 summarizes the experimental results for all tested configurations. The following nomenclature is used: $F$ is the maximum load registered during the test, $\tau_{A S T M}$ and $\tau_{R I L E M}$ are the maximum shear stresses at the centre of the panel according to the ASTM standard [58] and RILEM standard [59] respectively, $G_{A S T M}$ and $G_{R I L E M}$ are the shear modulus of elasticity according to the aforementioned standards and finally $\gamma_{y}, \gamma_{u}$ and $\mu$ are the yield strain, ultimate shear strain, and ductility factor computed according to 63 .

The repaired and retrofitted specimens (URM1_R and URM2_R) exhibited 


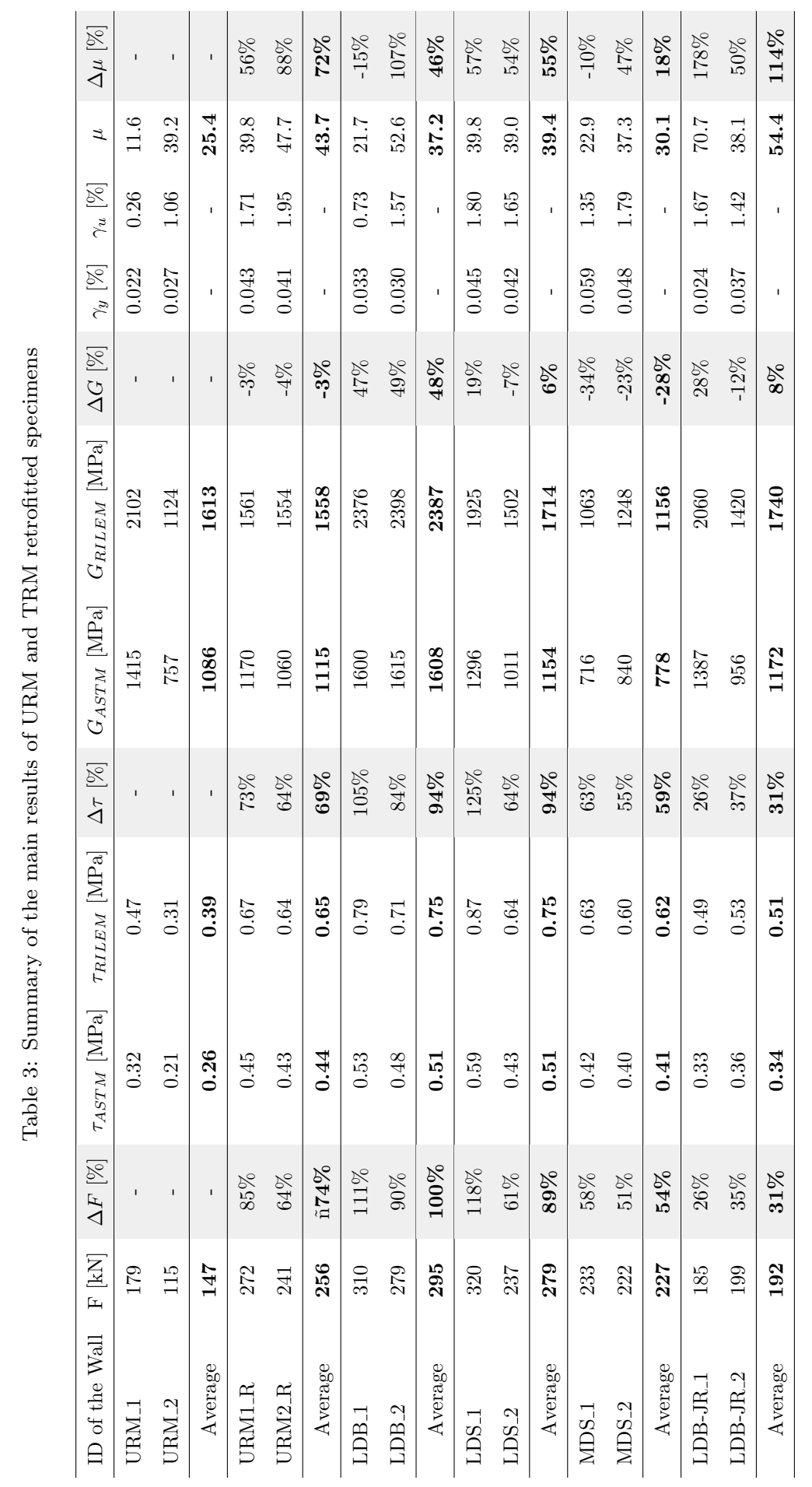


in all cases a higher strength capacity and ductility than the URM specimens. In terms of stiffness, they showed significant scattering probably due to the variability of masonry properties and the influence of the TRM layer at the beginning of the test. In fact, the contribution of the reinforcement in the initial elastic range may depend on the level of damage attained during the previous test and the effectiveness of the repair. In spite of it, these specimens provided satisfactory results in terms of deformability, as they were able to recover the initial stiffness of the URM original condition without experiencing a significant gain, which would be undesirable from a seismic resistant point of view 67, 68]. The specimens retrofitted with LDB achieved a significant increase of load bearing capacity and almost doubled the resistance of the URM specimens. In turn, the specimen repaired and retrofitted with LDB showed a capacity increment of $74 \%$. The application of the basalt grid continuous reinforcement reduced the variability of the overall shear-deformation response of the four walls investigated (both repaired-retrofitted and just retrofitted). The percentage increases of load bearing capacity are respectively 85\%, 64\%, $111 \%$ and $90 \%$ in specimens URM1_R, URM2_R, LDB_1, LDB_2 compared with the mean strength of the URM walls. In addition, the behaviour of the LDB specimens was characterized by a significant residual resistance owing to the higher ductility provided by the basalt grid. In fact the ductility increased $72 \%$ in the repair-retrofitted specimens (URM1_R and URM2_R) and 46\% in those just retrofitted (LDB_1 and LDB_2). No premature debonding from the masonry substrate was observed in any of the tests performed on walls retrofitted with LDB. The failure mode of the LDB was always rupture of the basalt yarns. The strengthening system revealed to be compatible with the original URM material since the surface did not undergo any detachment and consequently the stress transfer from the masonry substrate to the textile was achieved to the extent of allowing the fibres to reach their ultimate tensile capacity.

The four specimens reinforced with LDS and MDS textile presented similar behaviour, despite the difference in peak load detected in the first series (320 $\mathrm{kN}$ and $237 \mathrm{kN}$ ). The specimens retrofitted with LDS textile showed an average 
increase of $89 \%$ in terms of peak load compared to URM, whereas the increment was $54 \%$ for MDS textile. The lower spacing of yarns in MDS might explain this difference rates due the lower textile-matrix interlocking compared to the LDS. This behaviour is in agreement with the findings in [36], in which the reduction of the grid spacing of the textile led to a lower performance of the reinforcement. The different yarn spacing between LDS and MDS textiles, and therefore the different adherence of the textile to the matrix, caused different failure modes. Delamination within the matrix and debonding from substrate were observed in the post-peak stage of the MDS and LDS respectively, causing sudden drops of the capacity. Previous studies [35, 65, highlighted the importance of an effective textile-matrix interlocking in order to allow their proper cooperation and their combined debonding from the masonry substrate. For this reason, it seems that LDS performs better than MDS, since the latter exhibited premature textile-tomortar interface failure. It is important to highlight that failures of the yarns were observed neither in LDS nor in MDS, due to the high tensile strength of the steel cords.

The strengthening system with asymmetrical layout, i.e. continuous LDB in one side and JR with NSM rebars in the other, presented a moderate improvement of $31 \%$ in terms of peak load, with almost no increment of the initial shear stiffness. However, the most important outcome was the remarkable gain in ductility. After the cracking of the mortar joints, the original fragile behaviour of the URM material was turned into a ductile response by the combined LDB-JR system allowing an increase of ductility of more than $100 \%$. The overall behaviour of these specimens confirms that this novel solution could be useful to enhance the ductility of masonry façades with exposed bricks, in which the application of continuous TRM is feasible only on the inner face of the wall. The use of NSM rebars represents a minimally invasive reinforcement technique as highlighted by [31.

Figure 12 shows the rate of increment of each type of reinforcement configuration in terms of ductility and peak load. The graph considers the average results of each pair of specimens. The displayed histograms show visually the 
enhancement of capacity and ductility of the retrofitted specimens in comparison with the reference URM walls. TRM systems with LDB and LDS show to provide the best compromise between increase of resistance and ductility, meaning that a gain in strength is followed by a consistent improvement in the ductile behaviour of the specimen. In turn, MDS and the asymmetric LDB-JR systems yield much higher increase of one single property compared to the other one (much higher strength in MDS, much higher ductility in LDB-JR). In addition, the LDB textile have showed to be a very good retroffiting solution for damaged structures, as it increases both the structural capacity and the ductile behaviour of the specimens.

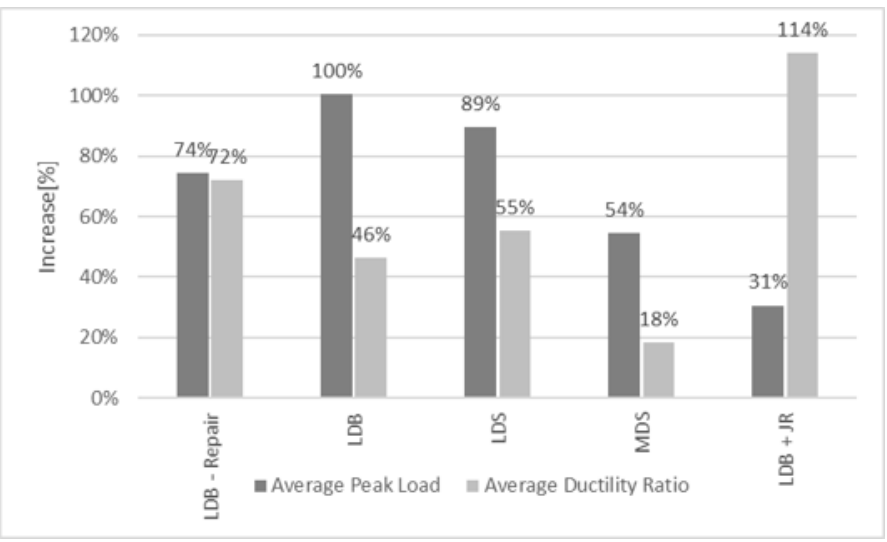

Figure 12: Rate of enhancement of ductility and peak load for all the retrofitted specimens

50

The experimental results have been compared with an analytical formulation for the prediction of the shear capacity of reinforced walls. The use of this formulation has been also used to evaluate the efficiency of the different types of reinforcements investigated. There are two guidelines available to predict the shear contribution of TRM reinforcement, the CNR-DT 200 [69], which mainly addresses the application of FRP and the CNR-DT 215 [17] for FRCM design. The present comparison is done with the formulation presented in [69] since it takes into account the strip configuration (LDS and MDS) while [17] is mostly oriented to full surface coverage TRM solutions. 
The nominal shear, $V_{t, R}$, is evaluated as the sum of the contribution of the masonry wall, $V_{m}$, and the reinforcement contribution, $V_{t, f}$, as shown in Equation 6. The reinforcement contribution, $V_{t, f}$ is calculated according to Equation 7 and 869 .

$$
\begin{gathered}
V_{t, R}=V_{m}+V_{t, f} \\
V_{t, f}=\frac{1}{\gamma_{R d}} \cdot 0.6 \cdot d \cdot 2 \cdot t_{f} \cdot \varepsilon_{f d} \cdot E_{f} \frac{b_{f}}{p_{f}} \quad \varepsilon_{f d} \cdot E_{f}=f_{f d} \\
\varepsilon_{f d}=\min \left\{\eta_{a} \cdot \frac{\varepsilon_{f k}}{\gamma_{f}}, \varepsilon_{f d d}\right\}
\end{gathered}
$$

The following notation is used in the previous equations: $\gamma_{R d}$ is the partial safety factor, $d$ is the length of the wall in the direction of the applied shear force, $t_{f}$ is the equivalent thickness of the reinforcement parallel to the applied shear force, $\varepsilon_{f d}$ is the strain corresponding to the reinforcement tensile capacity, $E_{f}$ is the Young's modulus of the textile, $f_{f d}$ is the reinforcement tensile capacity, $\varepsilon_{f k}$ represents the reinforcement strain at failure, $\varepsilon_{f d d}$ is the maximum strain at which the debonding takes place and $b_{f}$ and $p_{f}$ are the width and centreto-centre spacing of the TRM strips, respectively. In the case of full surface coverage the ratio $b_{f} / p_{f}$ is equal to 1 . The conversion factor $\eta_{a}$ and the partial factor $\gamma_{f}$ are defined from 69.

With the aim of performing a comparison with the experimental results, the partial safety factor $\gamma_{R d}$ is equated to 1 .

In order to apply Equation 7 to the experimental walls investigated in the present campaign, the design reinforcement strain $\varepsilon_{f d}$ is chosen according to the type of failure observed in the experiments and is multiplied by a coefficient $\alpha$, equal to 1.5, according to [17] since the failure was always evidenced in intermediate areas of the specimen. As a result, the tensile capacity $f_{f d}$ takes the value equal to $\sigma_{u, f}$ when the failure of the reinforcement is due to fibre rupture in tension, and the value $\sigma_{s l, t}$ (see Table 2 multiplied by $\alpha$ when the 
failure is due to debonding. The term $\sigma_{s l, t}$ is obtained from the single lap shear bond test following [17].

The exploitation ratio, which accounts for the percentage of the strip's usable tensile strength, is computed as the ratio between the tensile capacity of the reinforcement $f_{f d}$ and the ultimate tensile strength of the fibre $\sigma_{u, f}$ presented in Table 2. The calculation of the exploitation ratio for each reinforcement is presented in Table 4 .

Table 4: Comparison between the experimental values obtained and the analytical values computed according to the Italian guideline 69.

\begin{tabular}{|c|c|c|c|c|c|c|c|c|c|c|c|}
\hline ID & $V_{E X P}$ & $V_{m}$ & $V_{t, f, E X P}$ & & eometr & {$[\mathrm{mm}$} & & $f_{f d}$ & $V_{t, f}$ & Error & Exploitation Ratio \\
\hline Specimen & {$[\mathrm{kN}]$} & {$[\mathrm{kN}]$} & {$[\mathrm{kN}]$} & $\mathrm{d}$ & $t_{f}$ & $b_{f}$ & $p_{f}$ & {$[\mathrm{MPa}]$} & {$[\mathrm{kN}]$} & {$[\%]$} & $\frac{f_{f d}}{\sigma_{u, f}}$ \\
\hline LDB & 295 & 147 & 148 & 1270 & 0.032 & - & - & 1700.00 & 117,25 & -21 & 1.00 \\
\hline LDB_R & 272 & 147 & 125 & 1270 & 0.032 & - & - & 1700.00 & 117,25 & -7 & 1.00 \\
\hline LDS & 279 & 147 & 132 & 1270 & 0.084 & 100 & 250 & 2180.00 & 152.08 & 20 & 0.73 \\
\hline MDS & 227 & 147 & 80 & 1270 & 0.169 & 100 & 250 & 1260.00 & 183.58 & 128 & 0.42 \\
\hline
\end{tabular}

Table 4 presents the experimental values obtained from the DCT for the reinforced and unreinforced walls ( $V_{E X P}$ and $V_{m}$ respectively) and the analytical values computed using Equation $7 V_{t, f}$. The error is evaluated between the analytical value, $\left(V_{t, f}\right)$, and the experimental peak force sustained by the TRM strengthening system, $V_{t, f, E X P}$. The latter value is computed as the difference between the average shear force reached by the strengthened specimens, $V_{E X P}$, and the average shear force carried by the URM specimens, $V_{m}$.

Good agreement is obtained between the experimental and the analytical results for the LDB and LDB_R cases, which failed due to fibre rupture in tension, and the LDS case, having failed by debonding. Given the type of failure obtained, the exploitation ratio attains 1 in the first two cases. The exploitation ratio obtained for the LDS reinforced wall is 0.73. For the MDS reinforced wall, also failed due to debonding, significant disagreement is observed between the experimental and analytical results, which might be attributed to deficient bonding with the substratum induced by the yarn density. The large variability evidenced in the URM specimens can also explain the large disagreement of 
MDS since the $V_{t, f, E X P}$ is computed as the difference between the $V_{E X P}$ and the average URM shear capacity, $V_{m}$. In the MDS case, a low exploitation ratio, of only 0.42 is obtained.

\section{Conclusions}

This research has investigated the experimental shear behaviour of masonry walls retrofitted with TRM systems. The experimental programme has comprised diagonal compression tests of ten masonry samples reinforced in the laboratory with three different TRM systems, based respectively on continuous bidirectional grids of basalt TRM (LDB), discrete bands of unidirectional steel TRM (LDS and MDS, i.e. with low and medium yarn densities), and a novel asymmetric layout combining a basalt grid TRM on the wall's inner face and bed joints structural repointing with NSM helical stainless steel bars on the wall's outer face (LDB-JR). The main conclusions of the research can be summarized as follows:

- All the adopted TRM solutions have demonstrated to be fully compatible with the masonry substrate composed of solid clay bricks and lime mortar joints. No premature debonding failure occurred before the peak resistance in the TRM retrofitted walls.

- The application of TRM systems has improved the strength of the walls compared to the original URM material. The highest rates of enhancement have been found in LDB and LDS systems.

- The application of TRM systems has also remarkably improved the ductility of the walls compared to the original URM material, without altering the initial stiffness. These outcomes become of paramount importance in the seismic retrofit of existing masonry structures.

- The repair of cracks with a M15 lime based mortar together with continuous LDB grid applied symmetrically on damaged specimens has allowed a full recovery of the undamaged stiffness of the walls. This result shows 
the capability of the investigated technique for post-earthquake repair of existing masonry structures.

- The application of continuous LDB textile has reduced the scattering of the experimental results in comparison with the URM walls. This means that the TRM application can mitigate the possible influence of the variability of masonry properties and provide more homogeneous structural response.

- Unidirectional textiles of LDS and MDS fibres have provided qualitatively similar results, but the former has exhibited better performance in quantitative terms due to the better interlocking between the textile and the matrix. The increase of the yarn density does not necessarily lead to an improvement of the structural performance.

- All the adopted strengthening solutions have shown to be efficiently and easily to implementable. Among the four solutions, the application of LDB grid can be considered as the less time consuming, due to fact that applying a single surface layer is faster than applying a multiple strip configuration. The NSM system turns out to be the less invasive and the most reversible technique among the ones tested.

\section{Acknowledgements}

The authors gratefully acknowledge the financial support from the Ministry of Economy and Competitiveness and from the Ministry of Science, Innovation and Universities of the Spanish Government, as well as that of the ERDF (European Regional Development Fund) through projects MULTIMAS (Multiscale techniques for the experimental and numerical analysis of the reliability of masonry structures, ref. num. BIA2015-63882-P) and SEVERUS (Multilevel evaluation of seismic vulnerability and risk mitigation of masonry buildings in resilient historical urban centres, ref. num. RTI2018-099589-B-I00). The reinforcement systems and construction of the specimens for the experimental programme have been funded by Kerakoll Spa through the RTD project 
"Diagonal Compression Tests on Unreinforced and TRM Reinforced Masonry Walls" (ref. num. A-01217). The authors wish to thank Paolo Casadei, Patricio Contreras and José Luis Sanchez from Kerakoll Spa for their involvement and support. The support from Secretaria d'Universitats i Investigació de la Generalitat de Catalunya through a predoctoral grant awarded to the first author is also gratefully acknowledged.

\section{References}

[1] A. Penna, P. Morandi, M. Rota, C. F. Manzini, F. Da Porto, G. Magenes, Performance of masonry buildings during the Emilia 2012 earthquake, Bull. Earthq. Eng. 12 (2014) 2255-2273. doi:10.1007/s10518-013-9496-6.

[2] T. C. Triantafillou, Composites: a new possibility for the shear strengthening of concrete, masonry and wood, Compos. Sci. Technol. 58 (1998) 1285-1295. doi:10.1016/S0266-3538(98) 00017-7.

[3] T. C. Triantafillou, Strengthening of masonry structures using epoxybonded FRP laminates, Compos. Constr. 2 (2) (1998) 96-104. doi: 10.1061/(ASCE) 1090-0268(1998) 2:2(96)

[4] M. R. Valluzzi, F. Da Porto, C. Modena, Behaviour of multi-leaf stone masonry walls strengthened by different intervention techniques, Hist. Constr. (2001) 1023-1032.

URL http://www.civil.uminho.pt/masonry/Publications/ Historicalconstructions/page1023-1032\{_\}89\{_\}.pdf

[5] M. Corradi, C. Tedeschi, L. Binda, A. Borri, Experimental evaluation of shear and compression strength of masonry wall before and after reinforcement : Deep repointing, Constr. Build. Mater. 22 (2008) 463-472. doi:10.1016/j.conbuildmat.2006.11.021

[6] M. Corradi, A. Borri, A. Vignoli, Experimental Evaluation of In-plane Shear Behaviour of Masonry Walls Retrofitted Using Conventional and Innovative Methods, Mason. Int. J. Br. Mason. Soc. 21 (2008). 
[7] M. R. Valluzzi, D. Tinazzi, C. Modena, Shear behavior of masonry panels strengthened by FRP laminates, Constr. Build. Mater. 16 (2002) 409-416. doi:10.1016/S0950-0618(02)00043-0

[8] G. Marcari, G. Manfredi, A. Prota, M. Pecce, In-plane shear performance of masonry panels strengthened with FRP, Compos. Part B Eng. 38 (2007) 887-901. doi:10.1016/j.compositesb.2006.11.004.

[9] D. Foti, On the numerical and experimental strengthening assessment of tufa masonry with FRP, Mech. Adv. Mater. Struct. 20 (2) (2013) 163-175. doi:10.1080/15376494.2012.743634

[10] V. Alecci, S. Barducci, A. D'Ambrisi, M. De Stefano, F. Focacci, R. Luciano, R. Penna, Shear capacity of masonry panels repaired with composite materials: Experimental and analytical investigations, Compos. Part B Eng. 171 (March) (2019) 61-69. doi:10.1016/j.compositesb.2019.04. 013. URL https://doi.org/10.1016/j.compositesb.2019.04.013

[11] H. Maljaee, B. Ghiassi, P. B. Lourenço, D. V. Oliveira, FRP-brick masonry bond degradation under hygrothermal conditions, Compos. Struct. 147 (2016) 143-154. doi:10.1016/j.compstruct.2016.03.037. URL http://dx.doi.org/10.1016/j.compstruct.2016.03.037

[12] R. Ramirez, H. Maljaee, B. Ghiassi, P. B. Lourenço, D. V. Oliveira, Bond behavior degradation between FRP and masonry under aggressive environmental conditions, Mech. Adv. Mater. Struct. 26 (1) (2019) 6-14. doi:10.1080/15376494.2018.1534164.

[13] C. Mazzotti, F. Ferretti, B. Ferracuti, A. Incerti, Diagonal compression tests on masonry panels strengthened by FRP and FRCM, in: 10th Int. Conf. Struct. Anal. Hist. Constr., Taylor \& Francis Group, 2016, pp. 1069 1076 . 
[14] C. G. Papanicolaou, T. C. Triantafillou, K. Karlos, M. Papathanasiou, Textile-reinforced mortar (TRM) versus FRP as strengthening material of URM walls : in-plane cyclic loading, Mater. Struct. 40 (2007) 1081-1097. doi:10.1617/s11527-006-9207-8,

[15] ICC Evaluation Service, AC434 - Acceptance criteria for masonry and concrete strengthening using fabric-reinforced grout (SRG) composite systems (2017).

[16] American Concrete Institute, ACI 549.4R-13 - Guide to Design and Construction of Externally Bonded Fabric-Reinforced Cementitious Matrix (FRCM) Systems for Repair and Strengthening Concrete and Masonry Structures (2013).

[17] CNR - Consiglio Nazionale delle Ricerche, DT 215/2018 - Istruzioni per la progettazione, l'esecuzione ed il controllo di interventi di consolidamento statico mediante l'utilizzo di compositi fibrorinforzati a matrice inorganica (in Italian) (2018).

[18] N. Gattesco, C. Amadio, C. Bedon, Experimental and numerical study on the shear behavior of stone masonry walls strengthened with GFRP reinforced mortar coating and steel-cord reinforced repointing, Eng. Struct. 90 (2015) 143-157. doi:10.1016/j.engstruct.2015.02.024.

URL http://dx.doi.org/10.1016/j.engstruct.2015.02.024

[19] N. Reboul, Z. Mesticou, A. Si Larbi, E. Ferrier, Experimental study of the in-plane cyclic behaviour of masonry walls strengthened by composite materials, Constr. Build. Mater. 164 (2018) 70-83. doi:10.1016/j.conbuildmat.2017.12.215. URL http://linkinghub.elsevier.com/retrieve/pii/ S095006181732620X

[20] M. R. Valluzzi, C. Modena, G. De Felice, Current practice and open issues in strengthening historical buildings with composites, Mater. Struct. 47 (2014) 1971-1985. doi:10.1617/s11527-014-0359-7. 
[21] N. Ismail, R. B. Petersen, M. J. Masia, J. M. Ingham, Diagonal shear behaviour of unreinforced masonry wallettes strengthened using twisted steel bars, Constr. Build. Mater. 25 (2011) 4386-4393. doi:10.1016/j. conbuildmat.2011.04.063.

URL http://dx.doi.org/10.1016/j.conbuildmat.2011.04.063

[22] S. Ivorra, D. Bru, A. Galvañ, S. Silvestri, C. Apera, D. Foti, TRM reinforcement of masonry specimens for seismic areas, Int. J. Saf. Secur. Eng. 7 (4) (2017) 463-474. doi:10.2495/SAFE-V7-N4-463-474.

[23] N. Gattesco, I. Boem, Experimental and analytical study to evaluate the effectiveness of an in-plane reinforcement for masonry walls using GFRP meshes, Constr. Build. Mater. 88 (2015) 94-104. doi:10.1016/ j.conbuildmat.2015.04.014. URL http://dx.doi.org/10.1016/j.conbuildmat.2015.04.014

[24] A. Prota, G. Marcari, G. Fabbrocino, G. Manfredi, Experimental InPlane Behavior of Tuff Masonry strengthened with cementitious matrixgrid composites, Compos. Constr. 10 (2006) 223-233. doi:10.1061/(ASCE) 1090-0268(2006)10.

[25] A. Balsamo, M. Di Ludovico, A. Prota, G. Manfredi, Masonry walls strengthened with innovative composites. Am. Concr. Institute, ACI Spec. Publ. 275 (2011) 1-18.

URL http://www.scopus.com/inward/record.url?eid=2-s2. 0-84856850810\{\&\}partnerID=tZ0tx3y1

[26] M. Del Zoppo, M. Di Ludovico, A. Balsamo, A. Prota, In-plane shear capacity of tuff masonry walls with traditional and innovative Composite Reinforced Mortars (CRM), Constr. Build. Mater. 210 (2019) 289-300. doi:10.1016/j.conbuildmat.2019.03.133.

URL https://doi .org/10.1016/j . conbuildmat .2019.03.133

[27] X. Wang, C. C. Lam, V. P. Iu, Experimental investigation of in-plane shear behaviour of grey clay brick masonry panels strengthened with SRG, Eng. 
Struct. 162 (2018) 84-96. doi:10.1016/j .engstruct.2018.02.027.

URL https://doi.org/10.1016/j.engstruct.2018.02.027

[28] J. Yacila, J. Salsavilca, N. Tarque, G. Camata, Experimental assessment of confined masonry walls retrofitted with SRG under lateral cyclic loads, Eng. Struct. 199 (April) (2019). doi:10.1016/j.engstruct.2019.109555.

[29] N. Tarque, J. Salsavilca, J. Yacila, G. Camata, Multi-criteria analysis of five reinforcement options for Peruvian confined masonry walls, Earthquakes Struct. 17 (2) (2019) 205-219.

[30] M. Giaretton, D. Dizhur, E. Garbin, J. Ingham, F. Da Porto, In-plane strengthening of clay brick and block masonry walls using textile reinforced mortar, J. Compos. Constr. 22 (5) (2018) 1-10.

[31] S. Casacci, C. Gentilini, A. Di Tommaso, D. V. Oliveira, Shear strengthening of masonry wallettes resorting to structural repointing and FRCM composites, Constr. Build. Mater. 206 (2019) 19-34. doi:10.1016/j.conbuildmat.2019.02.044

URL https://linkinghub.elsevier.com/retrieve/pii/ S0950061819303393

[32] G. Giacomin, Innovative strengthening materials for the post-earthquake reconstruction of L'Aquila masonries, Struct. Anal. Hist. Constr. (2016) 330-336.

[33] M. Basili, F. Vestroni, G. Marcari, Brick masonry panels strengthened with textile reinforced mortar: experimentation and numerical analysis, Constr. Build. Mater. 227 (2019). doi:10.1016/j.conbuildmat.2019.117061. URL https://doi.org/10.1016/j.conbuildmat.2019.117061

[34] G. de Felice, S. De Santis, L. Garmendia, B. Ghiassi, P. Larrinaga, P. B. Lourenço, D. V. Oliveira, F. Paolacci, C. G. Papanicolaou, Mortar-based systems for externally bonded strengthening of masonry, Mater. Struct. 47 (2014) 2021-2037. doi:10.1617/s11527-014-0360-1. 
[35] M. Santandrea, I. Imohamed, C. Carloni, C. Mazzotti, S. de Miranda, F. Ubertini, A study of the debonding mechanism in steel and basalt FRCM masonry joints, Brick Block Mason. - Trends, Innov. Challenges (2016) 433-440.

[36] G. P. Lignola, C. Caggegi, F. Ceroni, S. De Santis, P. Krajewski, P. B. Lourenço, M. Morganti, C. C. Papanicolaou, C. Pellegrino, A. Prota, L. Zuccarino, Performance assessment of basalt FRCM for retrofit applications on masonry, Compos. Part B Eng. 128 (2017) 1-18. doi: 10.1016/j.compositesb.2017.05.003.

[37] A. Borri, G. Castori, M. Corradi, R. Sisti, Masonry wall panels with GFRP and steel-cord strengthening subjected to cyclic shear : An experimental study, Constr. Build. Mater. 56 (2014) 63-73.

[38] CEN. EN1998-3, Eurocode 8 : Design of structures for earthquake resistance - Part 3: Assessment and retrofitting of buildings. (2004).

[39] Ministero delle Infrastrutture e dei Trasporti, Circolare 2 febbraio 2009, n.617. Istruzioni per l'applicazione delle Nuove norme tecniche per le costruzioni (in italian). (2009).

[40] V. Alecci, M. Fagone, T. Rotunno, M. De Stefano, Shear strength of brick masonry walls assembled with different types of mortar, Constr. Build. Mater. 40 (2013) 1038-1045. doi:10.1016/j.conbuildmat.2012.11.107 URL http://dx.doi .org/10.1016/j.conbuildmat .2012.11.107

[41] M. Corradi, A. Borri, A database of the structural behavior of masonry in shear, Bull. Earthq. Eng. 16 (9) (2018) 3905-3930. doi:10.1007/ s10518-018-0328-6. URL https://doi .org/10.1007/s10518-018-0328-6

[42] C. L. Knox, D. Dizhur, J. M. Ingham, Experimental study on scale effects in clay brick masonry prisms and wall panels investigating compression and shear related properties, Constr. Build. Mater. 163 (2018) 706-713. 
doi:10.1016/j.conbuildmat.2017.12.149

URL https://doi .org/10.1016/j.conbuildmat .2017.12.149

[43] G. Magenes, G. M. Calvi, In-plane seismic response of brick masonry walls, Earthq. Eng. Struct. Dyn. 26 (1997) 1091-1112.

[44] E. Mustafaraj, Y. Yardim, Retrofitting damaged unreinforced masonry using external shear strengthening techniques, J. Build. Eng. 26 (August) (2019) 100913. doi:10.1016/j.jobe.2019.100913

URL https://doi .org/10.1016/j·jobe.2019.100913

[45] CEN, EN 772-1, Methods of test for masonry units. Part 1: Determination of compressive strength (2011).

[46] CEN, EN 772-6, Methods of test for masonry units. Part 6: Determination of bending tensile strength of aggregate concrete masonry units. (2002).

[47] CEN, EN 1015-11 - Methods of test for mortar for masonry - Part 11: Determination of flexural and compressive strength of hardened mortar. (1999).

[48] Kerakoll, Technical data sheet Biocalce MuroSano (2016).

[49] CEN, EN 998-2: Specification for mortar for masonry - Part 2: Masonry Mortar (2010).

[50] J. Segura, D. Aponte, L. Pelà, P. Roca, Influence of recycled limestone filler additions on the mechanical behaviour of commercial premixed hy-

q draulic lime based mortars, Constr. Build. Mater. (2019). doi:10.1016/ j.conbuildmat.2019.117722.

[51] European Committee for standardization, BS EN 1052-1:1999 -Methods of test for masonry - Part 1: Determination of compressive strength, Eur. Comm. Stand. (1999) 11.

[52] J. Segura, L. Pelà, P. Roca, Monotonic and cyclic testing of clay brick and lime mortar masonry in compression, Constr. Build. Mater. 193 (2018) 
453-466. doi:10.1016/j.conbuildmat.2018.10.198.

URL https://doi.org/10.1016/j.conbuildmat.2018.10.198

[53] Deutsche Norm, DIN 18555-9: Testing of mortar containing mineral binders - Part 9: Determining the compressive strength of hardened mortar. (1999).

[54] L. Pelà, K. Kasioumi, P. Roca, Experimental evaluation of the shear strength of aerial lime mortar brickwork by standard tests on triplets and non-standard tests on core samples, Eng. Struct. 136 (2017) 441-453. doi:10.1016/j.engstruct.2017.01.028.

[55] L. Pelà, P. Roca, A. Aprile, Combined In-Situ and Laboratory Minor Destructive Testing of Historical Mortars, Int. J. Archit. Herit. 12 (3) (2018) 334-349. doi:10.1080/15583058.2017.1323247.

URL https://doi.org/10.1080/15583058.2017.1323247

[56] Kerakoll, Technical data sheet Geocalce F Antisismico (2017).

[57] M. Santandrea, G. Daissè, C. Mazzotti, C. Carloni, An Investigation of the Debonding Mechanism between FRCM Composites and a Masonry Substrate, Key Eng. Mater. 747 (2017) 382-389. doi:10.4028/www. scientific.net/kem.747.382.

[58] ASTM, Standard Test Method for Diagonal Tension ( Shear ) in Masonry Assemblages (2000).

[59] RILEM Recommendation for Testing and Use of Construction Material, RILEM TC 76-LUM. Diagonal tensile strength of small wall specimens (1994).

[60] M. M. Frocht, Recent advances in photoelasticity and an investigation of the stress distribution in square blocks subjected to diagonal compression., Trans. ASME, Appl. Mech. Div. 53 (15) (1931).

[61] F. Parisi, I. Iovinella, A. Balsamo, N. Augenti, A. Prota, In-plane behaviour of tuff masonry strengthened with inorganic matrix-grid composites, 
Compos. Part B Eng. 45 (2013) 1657-1666. doi:10.1016/j.compositesb. 2012.09.068

URL http://dx.doi.org/10.1016/j.compositesb.2012.09.068

[62] G. Marcari, M. Basili, F. Vestroni, Experimental investigation of tuff masonry panels reinforced with surface bonded basalt textile-reinforced mortar, Compos. Part B 108 (2017) 131-142. doi:10.1016/j.compositesb. 2016.09 .094

URL http://dx.doi.org/10.1016/j.compositesb.2016.09.094

[63] N. Gattesco, I. Boem, A. Dudine, Diagonal compression tests on masonry walls strengthened with a GFRP mesh reinforced mortar coating, Bull. Earthq. Eng. 13 (2015) 1703-1726. doi:10.1007/s10518-014-9684-z. URL http://dx.doi.org/10.1007/s10518-014-9684-z

[64] N. Gattesco, I. Boem, Experimental and analytical study to evaluate the effectiveness of an in-plane reinforcement for masonry walls using GFRP meshes, Constr. Build. Mater. 88 (2015) 94-104. doi:10.1016/ j.conbuildmat.2015.04.014

URL http://dx.doi .org/10.1016/j.conbuildmat.2015.04.014

[65] S. De Santis, G. De Felice, Tensile behaviour of mortar-based composites for externally bonded reinforcement systems, Compos. Part B Eng. 68 (2015) 401-413. doi:10.1016/j.compositesb.2014.09.011. URL http://dx.doi.org/10.1016/j.compositesb.2014.09.011

[66] A. D'Ambrisi, L. Feo, F. Focacci, Experimental and analytical investigation on bond between Carbon-FRCM materials and masonry, Compos. Part B Eng. 46 (2013) 15-20. doi:10.1016/j.compositesb.2012.10.018. URL http://dx.doi.org/10.1016/j . compositesb.2012.10.018

[67] A. Benedetti, Diagonal Compression Behaviour of Masonry Walls Reinforced with FRM Coatings, Struct. Anal. Hist. Constr. An Interdiscip. Approach Rilem Bookseries 18 (2019) 474-483. doi:10.1007/ 978-3-319-99441-3_51. 
[68] S. Babaeidarabad, D. C, A. Nanni, URM walls strengthened with fabricreinforced cementitious matrix (FRCM) subjected to in-plane and out-ofplane load, in: J. Compos. Constr., Vol. 18, 2014. doi:10.1061/(ASCE) CC. 1943-5614.0000441.

[69] CNR-DT 200 R1/2013, Guide for the design and construction of externally bonded FRP systems for strengthening existing structures (2013). 